\section{Views of final-year student midwives on giving postpartum contraception and sexual health advice}

We read with interest McCance and Cameron's article $^{1}$ reporting the experiences and views of qualified midwives on giving postpartum contraceptive advice in the July 2014 issue of the Journal.

We would like to draw readers' attention to a complementary study that we carried out with final-year student midwives on a 3-year midwifery programme in a UK university. ${ }^{2}{ }^{3}$ This study reflects McCance and Cameron's finding that midwives find it difficult to give contraceptive advice, because of lack of privacy, lack of time and on occasions a lack of interest from women in the postnatal period, and also midwives feeling that they lacked knowledge of the topic. Midwifery students also reported a lack of confidence in their own knowledge, a perception that too little time was given to the topic in the midwifery curriculum, and a perception that their practice mentors (i.e. qualified midwives who support their learning when in clinical practice) were not themselves fully confident when giving contraceptive advice. However, student midwives felt strongly that the giving of contraceptive and sexual health advice was an important part of their role, and were keen to receive more training and to see such advice being given, by their mentors, in practice.

Our study also tested the competence of the students in giving such advice, by using a factual quiz based on practice-oriented scenarios. The findings indicated that the students either lacked knowledge or had difficulty translating theoretical knowledge into practical clinical situations.

We would echo McCance and Cameron's conclusion that qualified midwives need training and support from sexual and reproductive health services, but would add that midwifery curricula should place more emphasis on education about contraception and sexual health, and that midwives who are mentoring students, in particular, need support to feel more confident and knowledgeable about giving contraceptive advice to the women in their care.

\section{Susan Walker, PhD}

Senior Lecturer, Faculty of Health, Social Care and Education, Anglia Ruskin University, Chelmsford, UK; susan.walker@anglia.ac.uk

\section{Geraldine Davis, EdD}

Director, Doctorate in Education, Faculty of Health, Social Care and Education, Anglia Ruskin University, Chelmsford, UK; geraldine.davis@anglia.ac.uk

Competing interests None.

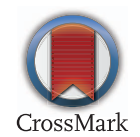

J Fam Plann Reprod Health Care 2014;40:312. doi:10.1136/jprhc-2014-101028

\section{REFERENCES}

1 McCance K, Cameron S. Midwives' experiences and views of giving postpartum contraceptive advice and providing long-acting reversible contraception: a qualitative study. J Fam Plann Reprod Health Care 2014;40: 177-183.

2 Davis G, Walker S. Learning at work and university: midwifery students and sexual health advice. Pract Res Higher Educ J 2013;7:63-77.

3 Walker SH, Davis G. Knowledge and reported confidence of final year midwifery students regarding giving advice on contraception and sexual health. Midwifery 2014;30:e169-e176. 